\title{
Molecular diagnosis of amoebiasis
}

\author{
Gabriela L. Calle-Pacheco ${ }^{1}$, Juan A. Jiménez-Chunga ${ }^{1}$, and Dan E. Vivas-Ruiz ${ }^{2 *}$ \\ ${ }^{1}$ Laboratorio de Parasitología en Fauna Silvestre y Zoonosis, Facultad de Ciencias Biológicas, Universidad Nacional Mayor de San Marcos; ${ }^{2}$ Laboratorio \\ de Biología Molecular, Facultad de Ciencias Biológicas, Universidad Nacional Mayor de San Marcos. Lima, Peru
}

\begin{abstract}
Amoebiasis is an intestinal parasitosis caused by the protozoan Entamoeba histolytica that represents the third leading cause of mortality due to parasitosis. It is a prevalent disease in tropical climate regions with poor or absent sanitary services. Microscopy and antigen detection techniques are routinely used to diagnose amoebiasis because of their low cost and ease of application. However, these techniques do not differentiate E. histolytica infections and other potentially pathogenic species such as Entamoeba moshkovskii or Entamoeba bangladeshi. Therefore, in the last decades, molecular tests that allow correct identification of the causal agent of amoebiasis and the establishment of the prevalence of the infecting species have been developed. Techniques based on nucleic acids, such as conventional, multiplex, or real-time polymerase chain reaction (PCR), are being seriously considered in clinical laboratories, because they detect the etiologic agent directly from the sample without the need for previous prolonged culture, thus reducing diagnostic time. Also, the nested PCR test and the sequencing of ribosomal markers have allowed the identification of new parasitic species in humans, such as E. moshkovskii and E. bangladeshi, and an improved characterization of the known infecting species. The application of multiplex platforms allows the simultaneous identification of infecting species, increasing the sensitivity and specificity of these techniques. Therefore, the molecular diagnosis of amoebiasis is projected as an innovative tool in the fight against this parasitosis.
\end{abstract}

Keywords: Amoebiasis. Entamoeba spp. Diagnostic. Molecular biology. PCR.

\section{Diagnóstico molecular de la amebiasis}

\section{Resumen}

La amebiasis es una parasitosis intestinal causada por el protozoario Entamoeba histolytica y representa la tercera causa de mortalidad por parasitosis. Es una enfermedad prevalente en regiones de clima tropical con deficientes o nulos servicios sanitarios. Las técnicas de microscopía y detección de antígenos se emplean sistemáticamente para el diagnóstico de la amebiasis por su bajo costo y fácil aplicación. Sin embargo, no permiten diferenciar entre infecciones por E. histolytica y otras especies de potencial patogenicidad como Entamoeba moshkovskii o Entamoeba bangladeshi. Ante ello, en las últimas décadas se han desarrollado pruebas moleculares que permiten una correcta identificación del agente causal de la amebiasis y el establecimiento de la prevalencia de la especie infectante. Las técnicas basadas en ácidos nucleicos, como la reacción en cadena de la polimerasa (PCR) convencional, múltiple o en tiempo real, están siendo seriamente consideradas en los laboratorios clínicos, porque detectan al agente etiológico de manera directa en la muestra sin necesidad de cultivo

\section{Correspondence:}

*Dan E. Vivas-Ruiz

E-mail: dvivasr@unmsm.edu.pe
Date of reception: 09-03-2021

Date of acceptance: 25-05-2021

DOI: 10.24875/BMHIM.21000044
Available online: 24-01-2022

Bol Med Hosp Infant Mex. 2022;79(1):3-16

www.bmhim.com

1665-1146/C 2021 Hospital Infantil de México Federico Gómez. Published by Permanyer. This is an open access article under the CC BY-NC-ND license (http://creativecommons.org/licenses/by-nc-nd/4.0/). 
prolongado previo, disminuyendo de esta forma el tiempo del diagnóstico. Asimismo, la PCR anidada sumada a la secuenciación de marcadores ribosomales ha permitido la identificación de nuevas especies parasitarias, como E. moshkovskii y E. bangladeshi en humanos, y una mejor caracterización de las especies infectantes ya conocidas. La aplicación de las plataformas multiplex permite la identificación simultánea de especies infectantes, aumentando la sensibilidad y la especificidad de estas técnicas. Por esto, el diagnóstico molecular de la amebiasis se proyecta como una verdadera herramienta innovadora en la lucha contra las parasitosis.

Palabras clave: Amebiasis. Entamoeba spp. Diagnóstico. Biología molecular. PCR.

\section{Introduction}

Amoebiasis is an infection in humans caused by the protozoan Entamoeba histolytica, an extracellular parasitic species classified as a category $B$ biodefense priority pathogen by the National Institute of Allergy and Infectious Diseases (NIAID) ${ }^{1,2}$. This parasitosis, considered the third leading cause of death by protozoa (resulting in 40,000 to 100,000 deaths per year) ${ }^{3-5}$, is prevalent in countries that have not yet achieved optimal health services. In other regions, such as Europe, Entamoeba infections are caused by travel activities to endemic regions or immigrants 6 . Worldwide, amoebiasis is considered one of the 15 leading causes of childhood diarrhea ${ }^{1}$ (in children $<2$ years of age) because its primary involvement is at the colon (amoebic colitis).

The World Health Organization (WHO) estimates that 500 million people worldwide may be infected with Entamoeba, but only $10 \%$ are infected with E. histolytica ${ }^{2}$. Also, about $80-90 \%$ of individuals with amoebiasis are asymptomatic ${ }^{7}$. For symptomatic patients, amoebiasis severity is influenced by the patient's genetics ${ }^{8,9}$, the genotype of the parasite ${ }^{10}$, and the microbiota or pathogenic microorganisms present in the gut ${ }^{11,12}$. These factors contribute to the spread of $E$. histolytica, leading to intestinal mucosa inflammation and tissue damage. Intestinal (dysentery) and extraintestinal (hepatic abscesses) complications are associated with mortality².

Routine diagnosis of amoebiasis is based on microscopic techniques, such as observing tetranucleated cysts or hematophagous trophozoites (Figure 1), or immunological techniques, such as antigen or antibody detection. Unfortunately, the existence of other non-pathogenic infecting Entamoeba species (with cysts morphologically identical to those of $E$. histolytica) or the inability to differentiate a recent infection from previous ones makes both techniques ineffective for specific diagnosis ${ }^{13,14}$.

For this reason, molecular tests have been developed based on the detection of parasite nucleic acids

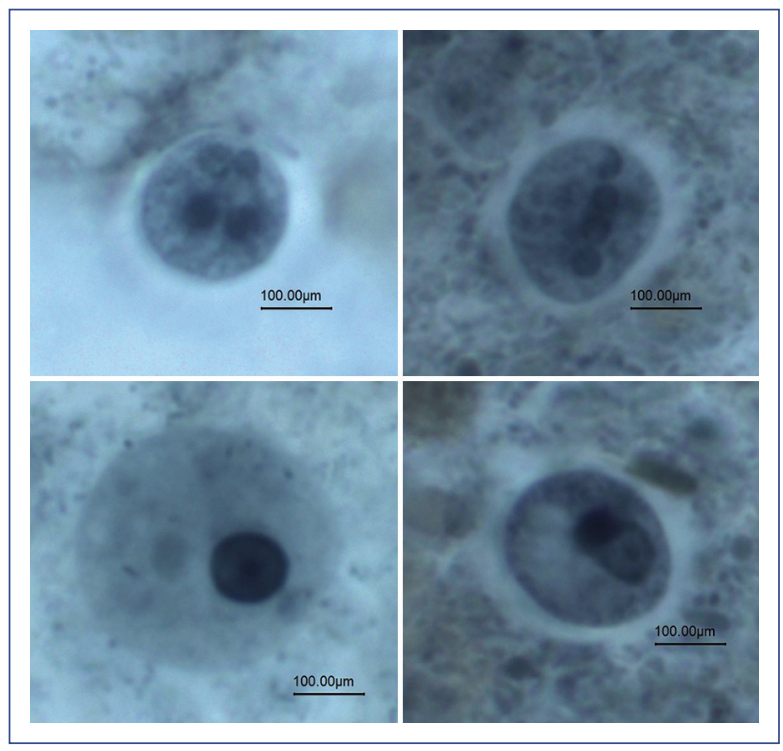

Figure 1. Forms of E. histolytica. Light microscopy images of tetranucleated cysts (top) and trophozoites (bottom) are shown.

by the polymerase chain reaction and its variants (nested, multiplex, and real-time PCR). These techniques resolve aspects of identification, taxonomy, epidemiology, and clinical importance; they also provide knowledge on the genetic diversity of Entamoeba species $^{15,16}$, which are associated with pathogenic ambiguity 17,18 . The application of this knowledge provides guidelines for the appropriate clinical management of amoebiasis.

The present review provides an overview of methodological strategies for diagnosing amoebiasis, a disease still considered undertreated in tropical and subtropical regions, by identifying $E$. histolytica, a species with morphology indistinguishable from other non-pathogenic species. We highlight the molecular techniques that have led to a better understanding of this parasitosis and the causative species. 


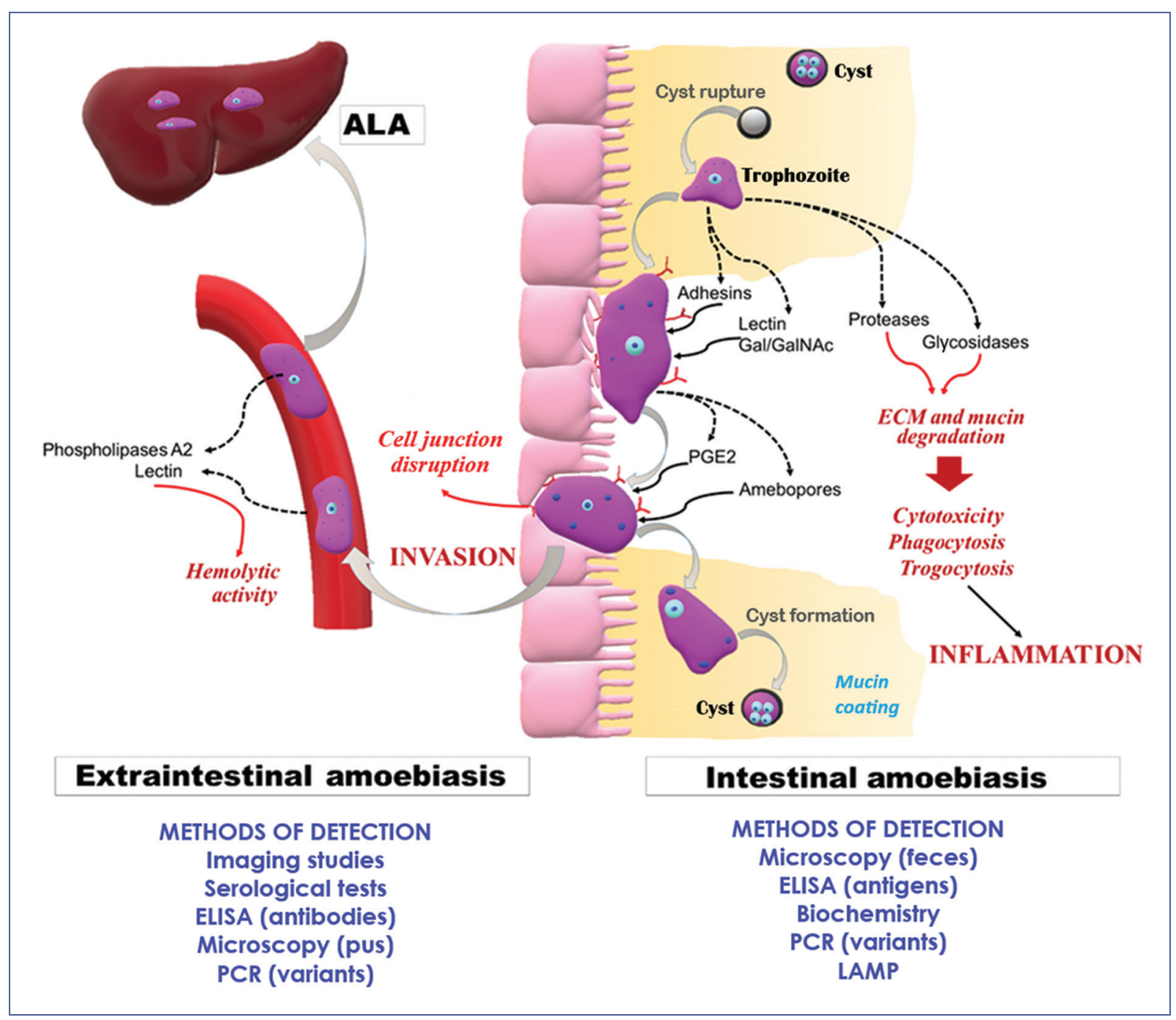

Figure 2. Steps in the infectious process of $E$. histolytica. Amoeba cysts reach the intestinal lumen, develop into trophozoites and colonize the intestinal mucosa and epithelium. The release of amoebic components (dashed black arrows) leads to the pathogenesis of $E$. histolytica: cell death, inflammation (red line), and invasive colonization (solid black arrows). Occasionally, access to the bloodstream allows dissemination into specific organs, including the liver, producing amoebic liver abscesses (ALA). The techniques commonly used for diagnosis both types of amoebiasis are also listed. ECM, extracellular matrix; PG2, prostaglandins E2.

\section{Pathology of E. histolytica}

Infection with $E$. histolytica occurs when food or water contaminated with the cyst form of the amoeba is consumed. Typically, the parasite is confined to the intestinal lumen of the host and feeds on bacteria, cellular debris, and food residues. In its trophozoite form, the amoeba can disperse along the intestinal mucosa as polyploid cells that adhere to the mucosa through the action of the lectin galactose/ $\mathrm{N}$-acetylgalactosamine (Gal/GalNAc), causing diarrhea and colitis ${ }^{19}$ (Figure 2).

The production and secretion of glucosidases and cysteine proteases by $E$. histolytica (EhCPs) confer resistance to physicochemical barriers such as mucins, secreted immunoglobulin A $(\lg A)$, and other antimicrobial molecules ${ }^{20}$. Additionally, trophozoites produce several molecules, such as amoebapores, prostaglandin E2, mucopolysaccharidases, and phospholipase $\mathrm{A}_{2}{ }^{19}$. These molecules are implicated in pathogenicity by producing effects such as contact-dependent and contact-independent cytotoxicity, hemolytic activity, phagocytosis, and trogocytosis ${ }^{19,21}$; the latter includes the participation of the AGC 1 family of kinases ${ }^{22}$. E. histolytica feeds on phagocytized erythrocytes and apoptotic and necrotic cells outside the intestinal lumen. This process apparently 
Table 1. Sensitivity of conventional methods for the diagnosis of amoebiasis

\begin{tabular}{|c|c|c|c|c|c|c|}
\hline Diagnosis method & $\begin{array}{l}\text { Identification of } \\
\text { E. histolytica }\end{array}$ & Sample & Sensitivity & Detection & $\begin{array}{l}\text { Time for } \\
\text { analysis }\end{array}$ & Reference \\
\hline Microscopy & No & Feces (fixed) & $25-60 \%$ & Trophozoites/cysts ${ }^{\mathrm{a}}$ & $1-2 \mathrm{~h}$ & 35 \\
\hline \multirow{2}{*}{$\begin{array}{l}\text { Culture and } \\
\text { isoenzyme analysis }\end{array}$} & \multirow[t]{2}{*}{ Yes } & \multirow{2}{*}{$\begin{array}{l}\text { Feces/ALA } \\
\text { aspirate }\end{array}$} & \multirow[t]{2}{*}{ Gold-standard } & \multirow[t]{2}{*}{ Zymodeme } & \multirow[t]{2}{*}{7 days } & 46 \\
\hline & & & & & & 5 \\
\hline \multirow[t]{2}{*}{ Antigen detection } & Yes & Feces & $85-100 \%$ & Fecal-antigens & \multirow[t]{2}{*}{$15-30 \mathrm{~min}$} & 46,58 \\
\hline & Yes & Serum & $95.7 \%^{c}$ & Lectin Gal/GalNAc & & 37 \\
\hline \multirow[t]{2}{*}{ Antibody detection } & Yes & Serum & $78 \%^{d}$ & \multirow[t]{2}{*}{$\lg M / \lg G$ anti-lectin } & \multirow[t]{2}{*}{$10 \mathrm{~min}$} & 37 \\
\hline & Yes & Serum & $>90^{\mathrm{e}}$ & & & 5 \\
\hline
\end{tabular}

aHematophagous trophozoites suggest the presence of $E$. histolytica, usually in patients with acute dysentery.

${ }^{b}$ Axenic culture media TYI-S-33 and YI-S, specific for E. histolytica.

'Serological analysis was performed before treatment with metronidazole. Sensitivity decreases to $34.8 \%$ after treatment.

dSerum from patients with acute amebic liver abscess.

e Sensitivity of $100 \%$ for patients with ALA and $>90 \%$ in serum from patients convalescing from infection.

Ig, immunoglobulin.

constitutes a virulence factor in avoiding detection by the immune system during tissue invasion ${ }^{2,23}$. The activity of EhCPs leads to disruption of extracellular matrix components and activation of metalloproteinases that destroy cell junctions to initiate extraintestinal invasion ${ }^{23}$. In some cases, the parasites can enter the portal vein and reach the liver, causing an amoebic liver abscess (ALA). In other cases, they infest the lungs or the brain, mainly in immunocompromised patients ${ }^{2,19}$. Untreated intestinal amoebiasis or ALA can lead to death ${ }^{2,19}$.

If not lethal, amoebiasis negatively influences growth and cognitive development in children ${ }^{24-26}$. Therefore, proper diagnosis of this parasitosis is necessary for effective treatment and improvement in the quality of life.

\section{Methods for routine diagnosis of amoebiasis}

Table 1 summarizes the methods that have been reported for the routine diagnosis of amoebiasis, indicating the sensitivity of each method. Most of these methods are particular in their methodology and are based on direct visualization of cysts or trophozoites or the presence of antigens or antibodies. Mainly, immunological strategies are not considered the reference technique, although they are widely used and allow the identification of $E$. histolytica ${ }^{13}$.

\section{Microscopy}

The classic diagnostic technique for parasitic infections is microscopy, used to identify hematophagous trophozoites and tetranucleated cysts in fecal samples $^{27}$, and also provides material for teaching and research ${ }^{28}$. Due to its simplicity is the method of choice in rural health centers in developing countries where amoebiasis is prevalent ${ }^{14}$. However, its efficacy depends on the skill of laboratory personnel in the correct identification of trophozoites since, in an immobile state, they can be confused with leukocytes, macrophages, and tissue cells. Additionally, rapid sample handling is required (20-30 $\mathrm{min}$ ), as the trophozoites are destroyed, resulting in false negatives ${ }^{29,30}$.

Microscopy has a sensitivity of $60 \%$ because identifications are only assigned as "Entamoeba complex." There is a limitation to differentiate species morphologically identical to E. histolytica at the level of the nucleus and tetranucleated cysts, such as E. dispar (non-pathogenic) and E. moshkovskii (of potential pathogenicity) ${ }^{18,27}$.

Innovations in this technique, such as using sample concentration by sedimentation ${ }^{31}$ or staining with ferric hematoxylin ${ }^{13}$, increase its sensitivity. For example, the use of hematoxylin allowed the differential identification of hematophagous trophozoites of $E$. histolytica in fecal samples and thus measured the prevalence $(11 \%)$ of this species in rural areas in Lima, Peru ${ }^{32}$.

\section{Biochemical method}

This method was considered the gold standard, although it is currently used more in the research field than in the clinical settings ${ }^{30}$. It employs fecal culture, followed by electrophoretic analysis of some enzymes 
(hexokinase, malate dehydrogenase, glucose phosphate isomerase, phosphoglucomutase, among others) to establish zymodemes as markers. The technique can accurately differentiate the presence of $E$. histolytica or $E$. dispar since they have different hexokinase enzymes $^{33}$. However, it has disadvantages for its application in epidemiology due to the long processing time (1 week), the requirement for special laboratory facilities, immediate processing of samples, interference from antiparasitic drugs in treated patients, and inability to identify other infecting Entamoeba species ${ }^{34}$. Additionally, the technique can give false-negative results opposite to those obtained by microscopy and has generally been used only for intestinal amoebiasis $^{29}$.

\section{Immunological techniques}

The enzyme-linked immunosorbent assay (ELISA) technique is based on detecting $E$. histolytica antigens in fresh fecal samples. This technique has higher sensitivity (80 to $94 \%)$ and specificity (94 to $100 \%)$ than microscopy and culture ${ }^{35}$. The most commonly used antigen is the Gal/GalNac adhesion lectin, detected by monoclonal antibodies in symptomatic and asymptomatic patients ${ }^{35}$. This lectin is highly conserved in E. histolytica and has antigenic characteristics different from the E. dispar lectin ${ }^{36}$. ELISA also allows the detection of serum antigen levels. However, its sensitivity is reduced (by $16 \%$ ) when there is prior treatment with antibiotics such as metronidazole, used to treat $\operatorname{ALA}^{37}$. Over the past 20 years, the use of ELISA kits has replaced both microscopy and the gold-standard method for clinical purposes because of the rapid results, the ability to differentiate $E$. histolytica and E. dispar, sensitivity and specificity, affordability, and large-scale diagnostic capability ${ }^{38,39}$.

Furthermore, along with other serological methods such as immunodiffusion, counterimmunoelectrophoresis, indirect hemagglutination, and immunoelectrophoresis, ELISA has been used to detect antibodies in the case of extraintestinal amoebiasis ${ }^{29}$. These methods detect anti-lectin Gal/GalNac IgG antibodies produced at high levels by patients infected with $E$. histolytica and absent in those infected with $E$. dispar. In acute E. histolytica infection, about $75-85 \%$ of patients develop high levels of antibodies, and more than $90 \%$ develop them once the infection is resolved (convalescent titers) $)^{40,41}$.
The detection of IgG usually favors epidemiological studies in regions with amoebiasis seroprevalences above $50 \%$; however, it limits the diagnosis of acute infections, so the combined application of this method with antigen detection is necessary ${ }^{37,42}$. Alternatively, the detection of IgM antibodies can be used; these antibodies do not persist over time and can be detected in periods of less than one week ${ }^{43}$.

\section{Molecular methods}

The application of methods based on amplifying DNA fragments to diagnose amoebiasis solved the problem of differentiating $E$. histolytica from other species ${ }^{44}$ and determining its prevalence and genetic differences ${ }^{45}$. PCR has greater sensitivity and specificity than microscopy and antigen detection ${ }^{44,46}$ and allows early detection of amoebiasis for timely treatment ${ }^{47}$. Species differentiation is achieved by amplifying DNA regions corresponding to single- or multi-copy genes.

The small ribosomal unit gene (18S rRNA) is the most widely used PCR marker for taxonomic differentiation between $E$. histolytica and $E$. dispar ${ }^{6,38}$. Other genes used are $30 \mathrm{kDa}$ antigen ${ }^{48}$, hemolysin $(H L Y 6)^{49}$, serine-rich E. histolytica protein $(S R E H P)^{50}$, actin ${ }^{51}$, cysteine protease $8(C P 8)^{3}$, and adhesin $(a d h 112)^{52}$.

With the use of PCR, it has been possible to identify new parasitic species in humans, such as E. moshkovskii (present among infants in Bangladesh) ${ }^{53}$, E. bangladeshi (in symptomatic and asymptomatic patients $)^{54}$, and the species E. coli, E. hartmanni, and E. polecki (commensal species), with morphology identical to E. histolytica and even with shared virulence factors ${ }^{55,56}$. Additionally, this technique detects mixed infections of E. histolytica and E. moshkovskii or E. dispar, the confluence of which is associated with gastrointestinal complications ${ }^{57}$. Table 2 shows the main PCR protocols and variants used as a reference for current studies.

\section{DNA extraction}

Like other molecular tests, the diagnosis of amoebiasis requires DNA of high purity and in sufficient quantity. Stool, the primary sample used, is a complex source of contaminants due to the presence of bacteria and human cells and a variety of metabolically derived substances, such as bile salts, which can interfere with or inhibit the amplification process ${ }^{57}$. Pre-incubation with bovine serum albumin is effective in removing 

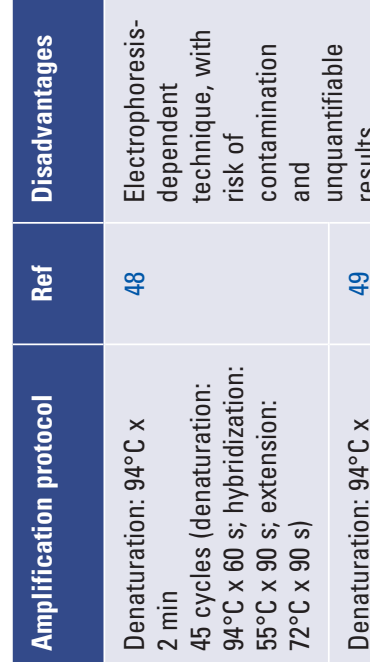

$\widehat{ธ}$

ฮั่

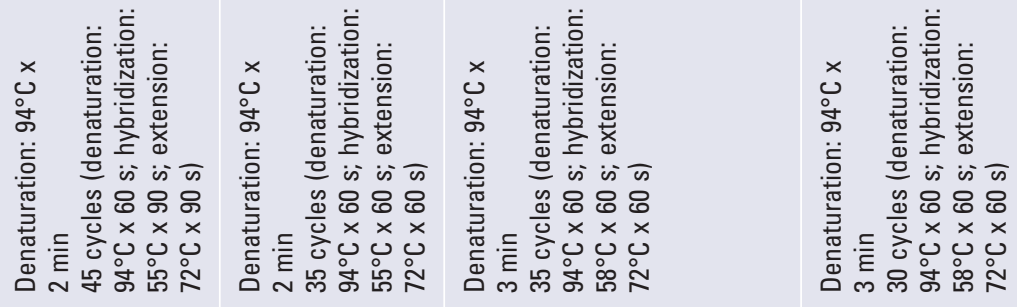

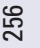

๕

๕ ํํㅇ

$\stackrel{\infty}{\frac{1}{4}}$

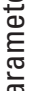

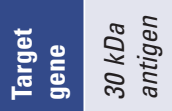

خे

$\sum_{\substack{5 \\ \Sigma}}$
$\infty$
$\infty$

$\underset{\substack{1 \\ \Sigma}}{\infty}$

产

듬

怘

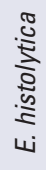

$\frac{\sqrt{2}}{\frac{2}{2}}$

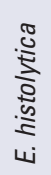

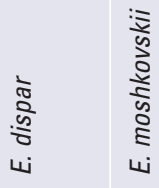

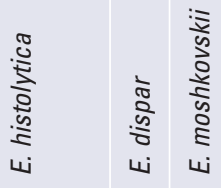

ఏ

$\stackrel{2}{2}$

ำ

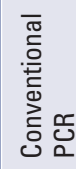

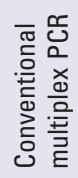




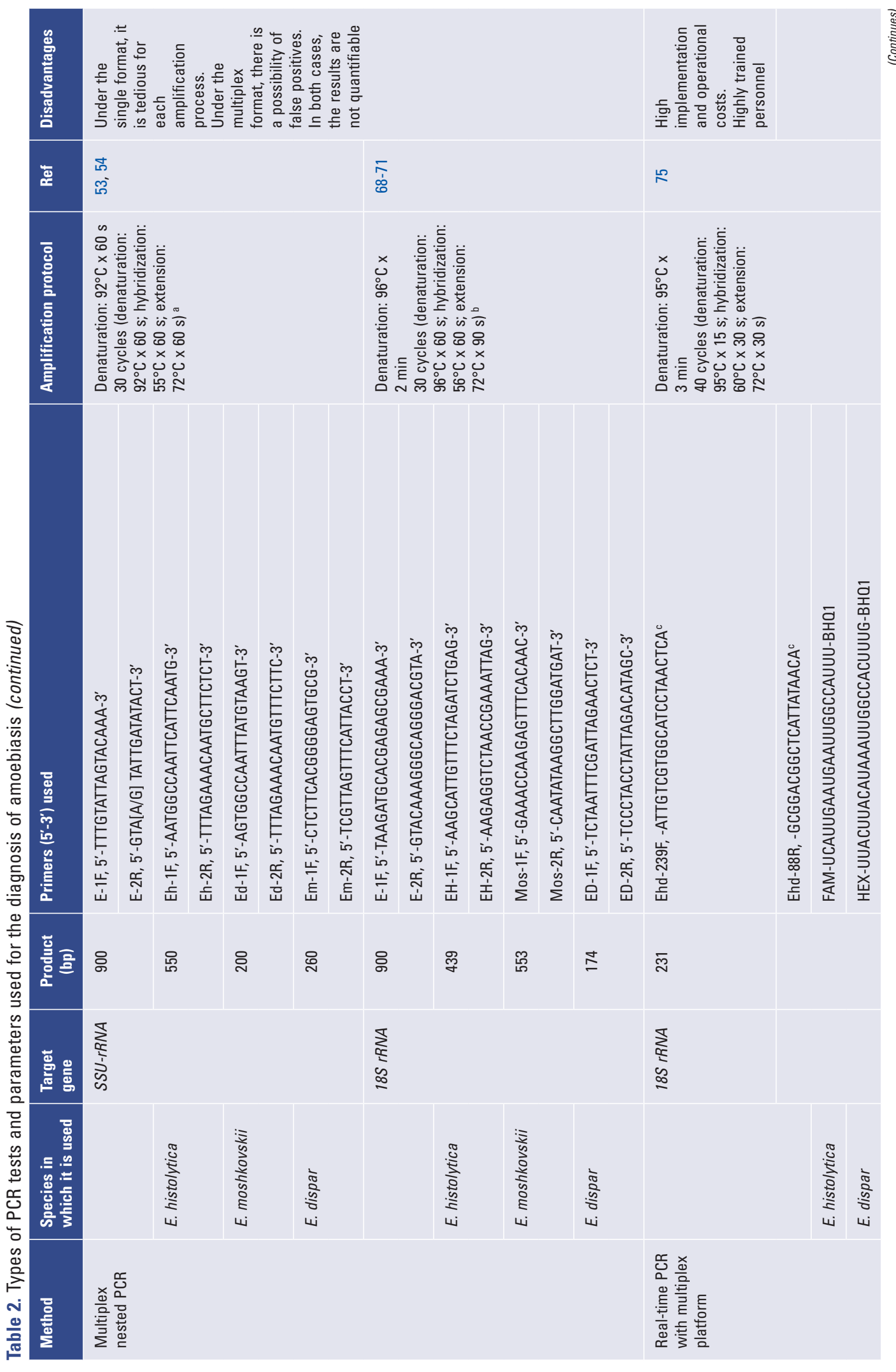




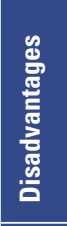

ळ

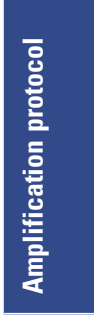

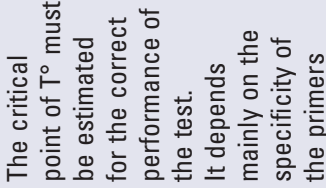

๖

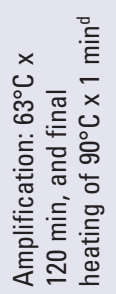

ஜ

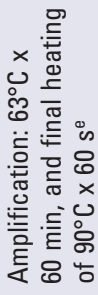

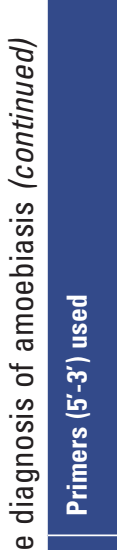
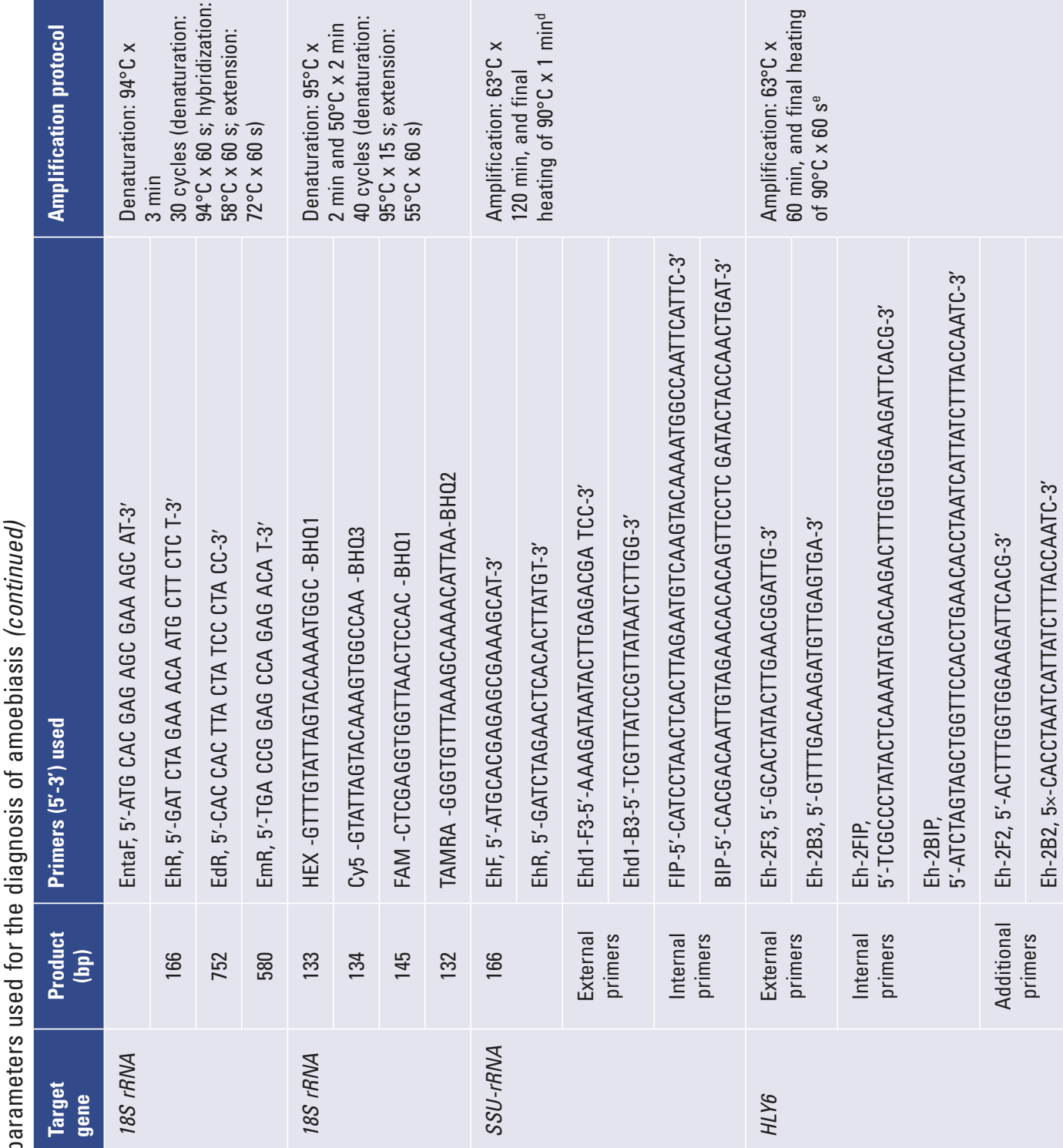

$\cong \check{尺}$

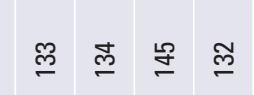

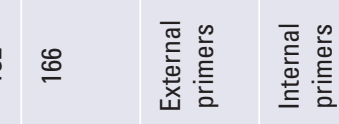

留要要

竞是

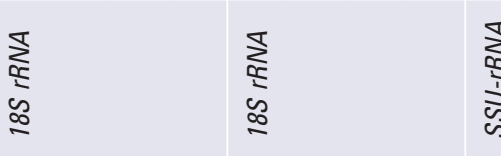

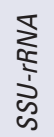

苩

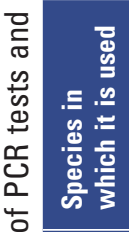

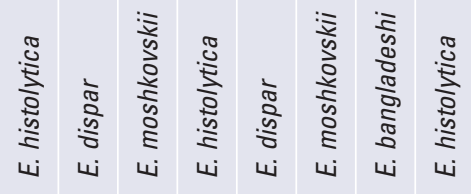

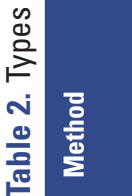

$\frac{\sqrt{2}}{3}$

$\sum_{j}^{0}$ 


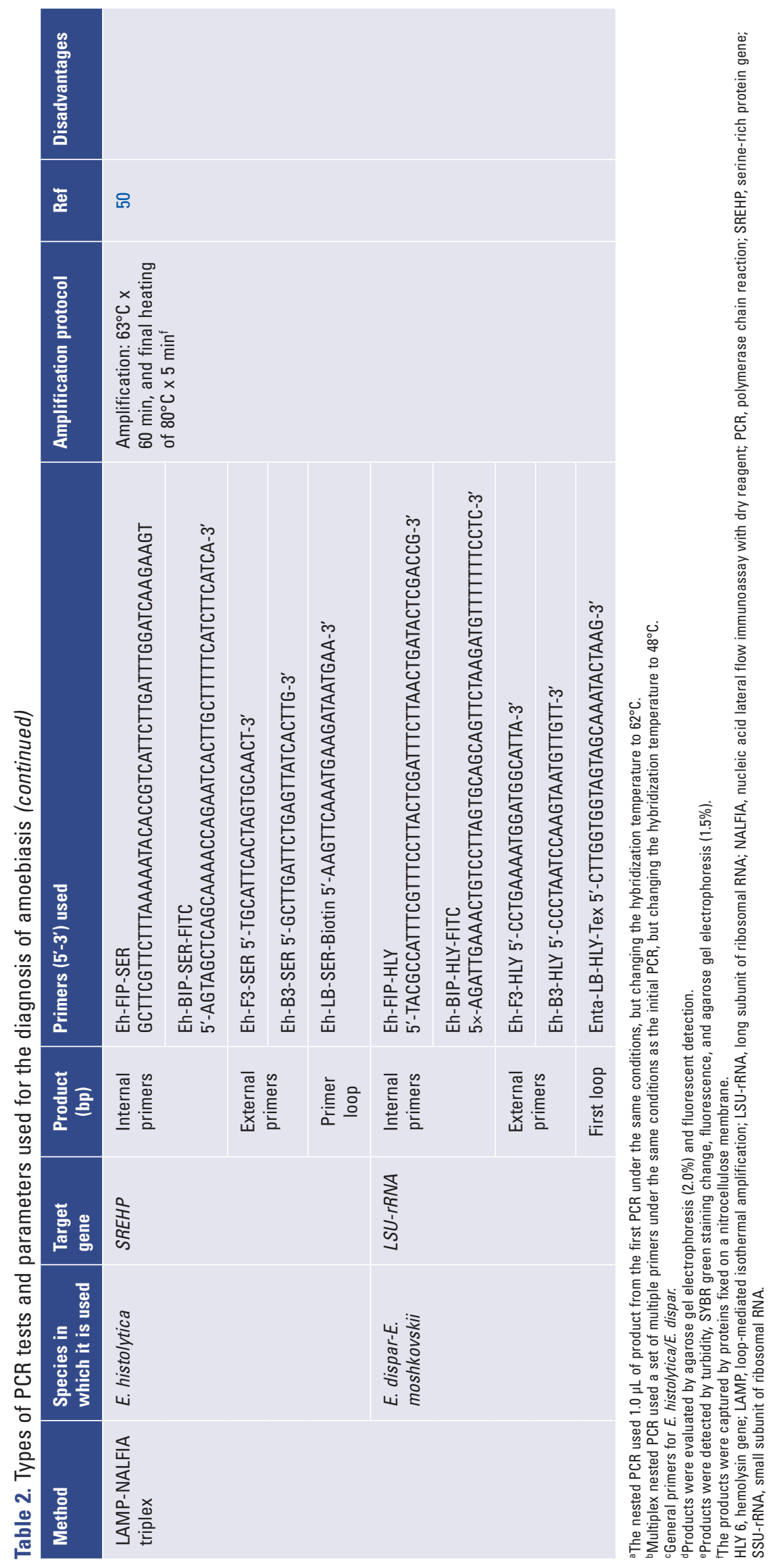


some of these contaminants ${ }^{55}$. Another factor to consider is the thickness of cyst walls, which makes them resistant to chemical and physical lysis ${ }^{58}$. For example, in the case of Cryptosporidium spp., the combination of thermal treatments (freezing and rapid thawing) showed good results in the fragmentation of the cyst walls ${ }^{59}$.

As a general protocol, the combined use of cetyltrimethylammonium bromide (CTAB), proteinase $\mathrm{K}$, and heat treatments effectively destroy cysts and trophozoites. The resulting DNA can then be precipitated with phenol/chloroform/isoamyl alcohol ${ }^{60}$.

In addition, there are commercial stool DNA extraction systems, such as the QIAamp Stool Mini Kit (QIAGEN), used for the differential diagnosis of Entamoeba species, which can correctly identify samples in $88 \%$ of cases $^{57}$.

\section{Conventional PCR}

The use of conventional PCR marked two fundamental milestones in the diagnosis of amebiasis: 1) the ability to determine the actual prevalence of the species $E$. histolytica and $E$. dispar, which routine methods had not been able to resolve ${ }^{61}$, and 2) to provide an effective diagnosis for the adequate treatment of the infec$\operatorname{tion}^{38}$. In fact, in patients with a positive microscopy diagnosis of $E$. histolytica-E. dispar, PCR-through the $18 S$ rRNA gene-allowed the identification of $E$. dispar as the most prevalent species ${ }^{61}$.

After the first report of $E$. moshkovskii in humans, the application of PCR for the diagnosis of amoebiasis became more important ${ }^{62}$. The development of new protocols for the simultaneous detection of $E$. histolytica, E. dispar, and E. moshkovskii species is based on a differential pattern of the core region size of the $18 \mathrm{~S}$ rRNA gene ${ }^{63}$. Studies based on this technique corroborate the high global prevalence of $E$. dispar, followed by $E$. moshkovskii at the regional level ${ }^{64}$, the latter being associated with diarrhea in children ${ }^{65}$.

Conventional PCR has higher specificity, sensitivity (97-99\%), and positivity than routine methods, including ELISA ${ }^{61,66}$, even when using small amounts of DNA obtained from fecal or culture samples ${ }^{44,67}$.

A variant of conventional PCR, PCR coupled to denaturing gradient gel electrophoresis (PCR-DGGE), employs urea and formaldehyde to create denaturing conditions and reliably discriminates $E$. histolytica from E. dispar ${ }^{52}$.

\section{Nested PCR}

Nested PCR protocols are generally used to increase detection sensitivity. They use previously amplified products as a template to perform a second PCR in which regions are amplified using internal anchor primers.

Nested PCR has been applied in different parts of the world to determine the actual prevalence of $E$. histolytica and the other species. This technique provided the first report of $E$. moshkovskii infection in Bangladesh by diagnosing amoebiasis in fecal samples from children $^{54}$. The technique shows the differential size of $18 S$ rRNA of E. histolytica, E. dispar, and E. moshkovskii by sequencing and correlating the results with the polymorphic sequences of the $\operatorname{Arg}^{\text {TCT }}$ tRNA gene of the three species ${ }^{53}$.

Based on the sensitivity and specificity of nested PCR in diagnosing amoebiasis, the group of Fotedar et al. ${ }^{5}$ developed a protocol including primers for the differential detection of $E$. moshkovskii, with results showing discrimination of the three species. Subsequent sequencing analyses gave $98.5 \%, 99.7 \%$, and $100 \%$ similarity percentages, with the sequences deposited at GenBank of E. dispar, E. histolytica, and E. moshkovskii, respectively ${ }^{5}$.

The innovation of multiplex nested PCR facilitates the simultaneous detection of $E$. histolytica, E. dispar, and E. moshkovskii, increasing the test's sensitivity even in complex samples and minimum concentrations of 1000 parasites/0.05 $\mathrm{g}$ of feces ${ }^{68}$. The $18 S$ rRNA gene (Table 2) in multiplex nested PCR allows differentiation of the three species, with a sensitivity and specificity of $94 \%$ and $100 \%$, respectively ${ }^{68}$.

In the epidemiological context, nested PCR established a higher prevalence for $E$. histolytica (75\%) over non-pathogenic species in Malaysian patients ${ }^{69}$. In contrast, in northwestern Iran, this technique placed $E$. dispar as the species with the highest prevalence $(0.58 \%)$ and reported the presence of $E$. moshkovskii for the first time in the region ${ }^{70}$. Additionally, in the United Arab Emirates, this technique changed the previously reported prevalence for $E$. histolytica (by microscopy) from $72 \%$ to $10 \%{ }^{71}$.

\section{Real-time PCR}

The real-time PCR (qPCR) or quantitative PCR method has gained interest in the field of amoebiasis diagnosis due to the optimization of the time used, the relative quantification of the number of parasites, and 
its high sensitivity ${ }^{72,73}$. In addition, this technique reduces the risk of contamination, the leading cause of false-positive results in conventional PCR amplification (dependent on electrophoresis ${ }^{74}$ ), and allows numerical understanding of the results ${ }^{75}$.

The technique employs primers and labeled probes that hybridize to specific sequences and are then detected and quantified through the fluorescence emitted after each amplification step. The probes show high performance in other nucleic acid detection platforms such as LUMINEX, achieving differential detection of Entamoeba species and other human protozoan parasites with a specificity similar to that obtained in simple real-time $\mathrm{PCR}^{76}$.

In diagnosing amoebiasis, probes (such as TaqMan) hybridize with the amplified products and achieve 100\% efficiency in identifying $E$. histolytica ${ }^{75}$. In samples with Iow DNA concentrations, qPCR can detect up to 0.5 trophozoites $/ \mathrm{mL}$ of stool, a concentration value that allows calculation of mean $C_{t}$ values ${ }^{75}$. In the case of fecal samples, the method's efficiency improves after applying freezing steps before extraction $\left(-20^{\circ} \mathrm{C} /-80^{\circ} \mathrm{C}\right)$ to maximize DNA detection expressed in decreasing $C_{t}$ values $^{77}$.

The use of Eswab brushes or DNA dilutions in saline phosphate buffer improves the technique's efficiency by reducing contaminants (soluble inhibitors) or normalizing sample volume, respectively ${ }^{78}$. Considering these factors and controlling the quality and quantity of extracted DNA, qPCR achieves remarkably low DNA detection limits of up to $0.2 \mathrm{pg}$ for $E$. histolytica and $2 \mathrm{pg}$ for E. dispar and E. moshkovskii, varying only the denaturation temperatures ${ }^{79}$.

Multiplex qPCR protocols (either duplex, triplex, or tetraplex) allow differential detection of the four Entamoeba species (E. histolytica, E. dispar, E. moshkovskii, and E. bangladeshi $)^{80}$. These protocols use primers common to all four species and Taqman probes that hybridize with the products and differ according to the fluorescent molecules they contain (FAM, VIC, fluorescein, among others) ${ }^{76}$. Currently, primers have been designed in the multiplex qPCR platform that can be applied in conventional versions of PCR, thus maintaining specificity in identification ${ }^{81}$. This strategy would be optimal mainly for sites where qPCR cannot be applied due to its high cost $^{81}$.

Currently, there are commercial qPCR panels, such as the singleplex and the arrays-TAG, which use Taqman probes and can detect up to 19 species of enteropathogens ranging from bacteria to helminths ${ }^{59,82}$. The detections are performed under universal conditions and use DNA extracted from bacteriophages to control the correct execution of DNA extraction and amplification, achieving a sensitivity of $85 \%$ and a specificity of $77 \%$ for detecting E. histolytica. Similarly, incorporating probes to detect $E$. dispar and E. moshkovskii is possible to provide additional diagnostic support compared to conventional PCR protocols ${ }^{59,82}$. Since E. histolytica, Giardia lamblia, and Salmonella spp. have been detected simultaneously in drinking water samples thanks to the protocols designed, the application of this methodology provides high levels of specificity ${ }^{83}$.

\section{Loop-mediated isothermal amplification}

Building on molecular methods based on polymerase amplification, researchers have developed other methodologies, such as nucleic acid sequence-based amplification (NASBA) ${ }^{84}$, self-sustained sequence replication $(3 S R)^{85}$, and strand displacement amplification (SDA $)^{86}$. These techniques modify conventional amplification by eliminating heat denaturation and using a set of transcription, reverse transcription, or restriction enzyme digestion reactions to reduce detection times and increase sensitivity and specificity. However, despite the efficiency of these methods (detection of fewer than ten copies of DNA in approximately one hour), they have some shortcomings and require expensive equipment ${ }^{87}$.

In 2000, Notomi et al. developed LAMP ${ }^{87}$ for the detection of hepatitis $B$ virus, improving detection limits of up to 6 DNA copies in 45 minutes by using a set of four specific primers: two internal direct (FIP) and two internal reverse (BIP) to amplify $6 \mathrm{HBs}$ regions of the virus. Each primer contains two different sequences corresponding to the sense and antisense sequences of the target DNA, which hybridize to different regions of the DNA and are then amplified under isothermal conditions by Bst DNA polymerase. The improved specificity, compared to PCR, lies in the use of primers designed explicitly for each reaction, whose $t_{m}$ are between the optimal temperatures of the Bst enzyme $\left(60-65^{\circ} \mathrm{C}\right)$ and which also recognize different sequences in the initial steps (without amplification). Subsequently, with two additional primers, the sequences present in the generated stem-loop are recognized ${ }^{87}$. A particular advantage of this technique is that the amplified DNA products can be observed with the naked eye as white precipitates in the reaction tube or by fluorescence if fluorescent intercalating dyes are incorporated. 
Since its development, LAMP has been successfully applied to detect different gastrointestinal parasites such as Fasciola hepatica, Opisthorchis spp. ${ }^{88}$, Schistosoma japonicum ${ }^{89}$, Taenia spp. ${ }^{90}$, and protozoa such as Cryptosporidium spp. in fecal and water samples $^{91}$. The design of specific primers, melting temperatures, and negative controls are critical to ensure that the amplification reaction is effective.

In the diagnosis of amoebiasis, LAMP allows the detection of $E$. histolytica up to one parasite per reaction, amplifying regions of the $18 \mathrm{~S}$ rRNA gene (Table 2) with a sensitivity of 15 to 50 parasites compared to nested PCR and a specificity of $92 \%$, which makes it the most uncomplicated technique to apply with high specificity $^{92}$. Another LAMP-compatible marker is the hemolysin gene (HLY6), which achieves a sensitivity of five parasites per reaction and whose specificity was tested against E. dispar, Blastocystis hominis, and Escherichia coli, showing no results for these species. Positive reactions for $E$. histolytica were identified as tube turbidity or staining changes using SYBR green. Additionally, LAMP has demonstrated $100 \%$ specificity compared to nested PCR from ALA pus samples with detection limits of 1 pg DNA, even detecting new cases beyond those reported by $\mathrm{PCR}^{93}$.

Currently, LAMP has already been adapted to qPCR protocols ${ }^{94}$ and to the thermostabilized triplex strategy, which, together with a dry-reagent nucleic acid lateral flow immunoassay (NALFIA), allows the simultaneous and differential detection of E. histolytica, E. dispar, and E. moshkovskii, facilitating the visualization and interpretation of the amplicons produced by LAMP ${ }^{50}$. In LAMP-NALFIA, the primers for E. histolytica correspond to the specific sequences of the SREHP gene, while for E. dispar and E. moshkovskii, they correspond to the large subunit of the ribosomal RNA gene (LSUrRNA) (Table 2), which are double-labeled by haptens and fluorescent molecules. The technique allows detection limits of ten $E$. histolytica trophozoites per reaction to be obtained with a specificity of $100 \%$, although its ability to discriminate infecting species needs to be improved ${ }^{50}$. However, it has shown better performance than PCR, $\mathrm{PPCR}$, and nested PCR ${ }^{95,96}$.

Considering that LAMP allows detection with high sensitivity and specificity without the need for expensive equipment compared to the PCR techniques described, its application for the diagnosis of amoebiasis is relevant in the development of protocols that allow differentiation between $E$. histolytica and $E$. moshkovskii. Furthermore, LAMP could be applied in ordinary circumstances, decreasing the risk of disease severity and identifying small outbreaks in countries where amoebiasis is endemic, and resources are scarce.

In conclusion, the impact of $E$. histolytica infections on children's health in rural areas of developing countries requires effective diagnostic methodologies. Molecular methodologies have consistently contributed to the understanding of amoebiasis, for example, the actual prevalence of $E$. histolytica and the clinical significance that E. moshkovskii species may have. Furthermore, these techniques significantly reduce the time to obtain an accurate diagnosis with the added benefit of simultaneously detecting a broad panel of gastrointestinal parasites, bacteria, and viruses. However, the need for a practical diagnostic test is linked to the feasibility of its application, so the operational and logistical reality of health centers should be considered. In these circumstances, molecular techniques (PCR, qPCR, and nested PCR) have a restricted mass use. However, innovations such as LAMP offer opportunities for diagnosis with a higher degree of sensitivity and specificity than routine techniques, so it is necessary to evaluate their performance on site.

\section{Ethical disclosures}

Protection of human and animal subjects. The authors declare that no experiments were performed on humans or animals for this study.

Confidentiality of data. The authors declare that they have followed the protocols of their work center on the publication of patient data.

Right to privacy and informed consent. The authors declare that no patient data appear in this article.

\section{Conflicts of interest}

The authors declare no conflict of interest.

\section{Funding}

None.

\section{Acknowledgments}

This review is part of the development of Gabriela Calle's thesis in the Molecular Biology Program (Programa de Biología Molecular) at UNMSM. The first author thanks Ana Pacheco and Hugo Calle for their support in the conception and elaboration of the first 
draft of the manuscript. In addition, thanks are due to Dr. Pedro Palermo for the critical review of the manuscript.

\section{References}

1. Shirley DT, Farr L, Watanabe K, Moonah S. A review of the global burden, new diagnostics, and current therapeutics for amebiasis. Open Forum Infect Dis. 2018:5:ofy161.

2. Carrero JC, Reyes-López M, Serrano-Luna J, Shibayama M, Unzueta J, León-Sicarios N, et al. Intestinal amoebiasis: 160 years of its first detection and still remains as a health problem in developing countries. Int $J$ Med Microbiol. 2020;310:151358.

3. Najafi A, Mirzaei A, Kermanjani A, Abdi J, Ghaderi A, Naserifar R. Molecular identification of Entamoeba histolytica from stool samples of llam Iran. Comp Immunol Microbiol Infect Dis. 2019;63:145-7.

4. Domínguez M. Amebiasis intestinal y hepática. Gastroenterol Latinoam. 2018;29:50-3

5. Fotedar R, Stark D, Beebe N, Marriott D, Ellis J, Harkness J. Laboratory diagnostic techniques for Entamoeba species. Clin Microbiol Rev. 2007;20:511-32.

6. Cui Z, Li J, Chen Y, Zhang L. Molecular epidemiology, evolution, and phylogeny of Entamoeba spp. Infect Genet Evol. 2019;75:104018.

7. Ximénez C, Morán P, Rojas L, Valadez A, Gómez A. Reassessment of the epidemiology of amebiasis: state of the art. Infect Genet Evol. 2009;9:1023-32.

8. Duggal P, Guo X, Haque R, Peterson KM, Ricklefs S, Mondal D, et al. A mutation in the leptin receptor is associated with Entamoeba histolytica infection in children. J Clin Invest. 2011;121:1191-8.

9. Duggal P, Haque R, Roy S, Mondal D, Sack RB, Farr BM, et al. Influence of human leukocyte antigen class II alleles on susceptibility to Entamoeba histolytica infection in Bangladeshi children. J Infect Dis. 2004;189:520-6.

10. Ali IK, Mondal U, Roy S, Haque R, Petri WA Jr, Clark CG. Evidence for a link between parasite genotype and outcome of infection with Entamoeba histolytica. J Clin Microbiol. 2007;45:285-9.

11. Burgess SL, Petri WA Jr. The intestinal bacterial microbiome and E. histolytica infection. Curr Trop Med Rep. 2016;3:71-4.

12. Ankri S. Entamoeba histolytica-gut microbiota interaction: more than meets the eye. Microorganisms. 2021;9:581.

13. Chacín-Bonilla L. Amebiasis: aspectos clínicos, terapéuticos y de diagnóstico de la infección. Rev Med Chile. 2013;141:609-15.

14. Chacín-Bonilla L. Diagnóstico microscópico de amibiasis: método obsoleto pero necesario en el mundo en desarrollo. Invest Clin. 2011;52:291-4.

15. Gilchrist CA, Ali IK, Kabir M, Alam F, Scherbakova S, Ferlanti E, et al. A multilocus sequence typing system (MLST) reveals a high level of diversity and a genetic component to Entamoeba histolytica virulence. BMC Microbiol. 2012;12:151.

16. Stensvold CR, Lebbad M, Victory EL, Verweij JJ, Tannich E, Alfellani M, et al. Increased sampling reveals novel lineages of Entamoeba: consequences of genetic diversity and host specificity for taxonomy and molecular detection. Protist. 2011:162:525-41.

17. Kyany'a C, Eyase F, Odundo E, Kipkirui E, Kipkemoi N, Kirera R, et al. First report of Entamoeba moshkovskii in human stool samples from symptomatic and asymptomatic participants in Kenya. Trop Dis Trave Med Vaccines. 2019;5:23.

18. Heredia RD, Fonseca JA, López MC. Entamoeba moshkovskii perspectives of a new agent to be considered in the diagnosis of amebiasis. Acta Trop. 2012;123:139-45.

19. Marie C, Petri WA Jr. Regulation of virulence of Entamoeba histolytica. Annu Rev Microbiol. 2014;68:493-520.

20. Mortimer L, Chadee K. The immunopathogenesis of Entamoeba histolytica. Exp Parasitol. 2010;126:366-80.

21. Ralston KS, Solga MD, Mackey-Lawrence NM, Somlata, Bhattacharya A Petri WA Jr. Trogocytosis by Entamoeba histolytica contributes to cell killing and tissue invasion. Nature. 2014;508:526-30.

22. Somlata, Nakada-Tsukui K, Nozaki T. AGC family kinase 1 participates in trogocytosis but not in phagocytosis in Entamoeba histolytica. Nat Commun. 2017;8:101.

23. Muliani N, Salim HM. Review article: Amebiasis molecular pathogenesis development. Med Health Sci J. 2019;3:6.

24. Haque R, Mondal D, Duggal P, Kabir M, Roy S, Farr BM, et al. Entamoeba histolytica infection in children and protection from subsequent amebiasis. Infect Immun. 2006;74:904-9.

25. Mondal D, Petri WA Jr, Sack RB, Kirkpatrick BD, Haque R. Entamoeba histolytica associated diarrheal illness is negatively associated with the growth of preschool children: evidence from a prospective study. Trans R Soc Trop Med Hyg. 2006;100:1032-8.
26. Zavala GA, van Dulm E, Doak CM, García OP, Polman K, Campos-Ponce M. Ascariasis, amebiasis and giardiasis in Mexican children: distribution and geographical, environmental and socioeconomic risk factors. J Parasit Dis. 2020;44:829-36.

27. van Lieshout L, Verweij JJ. Newer diagnostic approaches to intestinal protozoa. Curr Opin Infect Dis. 2010;23:488-93.

28. Zerpa R, Náquira C, Espinoza Y. Una nueva visión de Entamoeba histolytica. Rev Peru Med Exp Salud Publica. 2007;24:190-92.

29. López MC, Quiroz DA, Pinilla AE. Diagnóstico de amebiasis intestinal y extraintestinal. Acta Med Colomb. 2008;33:75-83.

30. Parija SC, Mandal J, Ponnambath DK. Laboratory methods of identification of Entamoeba histolytica and its differentiation from look-alike Entamoeba spp. Trop Parasitol. 2014;4:90-5.

31. Terashima A, Marcos L, Maco V, Canales M, Samalvides F, Tello R. Técnica de sedimentación en tubo de alta sensibilidad para el diagnóstico de parásitos intestinales. Rev Gastroenterol Perú. 2009;29:305-10.

32. Garaycochea MC, Beltrán FM. Parasitosis intestinales en zonas rurales de cuatro provincias del departamento de Lima. Lima: Instituto Nacional de Salud; 2018.

33. Jackson TF, Suparsad S. Zymodeme stability of Entamoeba histolytica and E. dispar. Arch Med Res. 1997;28:304-5.

34. Haque R, Faruque AS, Hahn P, Lyerly DM, Petri WA Jr. Entamoeba histolytica and Entamoeba dispar infection in children in Bangladesh. $\mathrm{J}$ Infect Dis. 1997;175:734-6.

35. Haque R, Neville LM, Hahn P, Petri WA Jr. Rapid diagnosis of Entamoeba infection by using Entamoeba and Entamoeba histolytica stool antigen detection kits. J Clin Microbiol. 1995;33:2558-61.

36. López OY, López MC, Corredor V, Echeverri MC, Pinilla AE. Diferenciación del complejo Entamoeba histolytica/Entamoeba dispar mediante Gal/ GalNAc-lectina y PCR en aislamientos colombianos. Rev Med Chile. 2012;140:476-83.

37. Haque R, Mollah NU, Ali IK, Alam K, Eubanks A, Lyerly D, et al. Diagnosis of amebic liver abscess and intestinal infection with the TechLab Entamoeba histolytica II antigen detection and antibody tests. J Clin Microbiol. 2000;38:3235-9.

38. Saidin S, Othman N, Noordin R. Update on laboratory diagnosis of amoebiasis. Eur J Clin Microbiol Infect Dis. 2019;38:15-38.

39. Tanyuksel M, Petri WA Jr. Laboratory diagnosis of amebiasis. Clin Microbiol Rev. 2003;16:713-29.

40. Ravdin JI, Jackson TF, Petri WA Jr, Murphy CF, Ungar BL, Gathiram V, et al. Association of serum antibodies to adherence lectin with invasive amebiasis and asymptomatic infection with pathogenic Entamoeba histolytica. J Infect Dis. 1990;162:768-72.

41. Caballero-Salcedo A, Viveros-Rogel M, Salvatierra B, Tapia-Conyer R, Sepulveda-Amor J, Gutierrez G, et al. Seroepidemiology of amebiasis in Mexico. Am J Trop Med Hyg. 1994;50:412-9.

42. Haque R, Ali IM, Petri WA Jr. Prevalence and immune response to Entamoeba histolytica infection in preschool children in Bangladesh. Am J Trop Med Hyg. 1999;60:1031-4.

43. Abd-Alla MD, Jackson TG, Ravdin Jl. Serum IgM antibody response to the galactose-inhibitable adherence lectin of Entamoeba histolytica. Am J Trop Med Hyg. 1998;59:431-4.

44. Haque R, Ali IK, Akther S, Petri WA Jr. Comparison of PCR, isoenzyme analysis, and antigen detection for diagnosis of Entamoeba histolytica infection. J Clin Microbiol. 1998;36:449-52.

45. Fotedar R, Stark D, Beebe N, Marriott D, Ellis J, Harkness J. PCR detection of Entamoeba histolytica, Entamoeba dispar, and Entamoeba moshkovskii in stool samples from Sydney, Australia. J Clin Microbiol. 2007:45:1035-7.

46. Huston CD, Haque R, Petri WA Jr. Molecular-based diagnosis of Entamoeba histolytica infection. Expert Rev Mol Med. 1999;1999:1-11.

47. Madden GR, Shirley DA, Townsend G, Moonah S. Lower gastrointestinal bleeding due to Entamoeba histolytica detected early by multiplex PCR: case report and review of the laboratory diagnosis of amebiasis. Am J Trop Med Hyg. 2019;101:1380-3.

48. Zaman S, Khoo J, Ng SW, Ahmed R, Khan MA, Hussain R, et al. Direct amplification of Entamoeba histolytica DNA from amoebic liver abscess pus using polymerase chain reaction. Parasitol Res. 2000;86:724-8.

49. Zindrou S, Orozco E, Linder E, Téllez A, Björkman A. Specific detection of Entamoeba histolytica DNA by hemolysin gene-targeted PCR. Acta Trop. 2001;78:117-25.

50. Foo PC, Chan YY, Mohamed M, Wong WK, Nurul Najian AB, Lim BH. Development of a thermostabilised triplex LAMP assay with dry-reagent four target lateral flow dipstick for detection of Entamoeba histolytica and non-pathogenic Entamoeba spp. Anal Chim Acta. 2017; 966:71-80.

51. Freitas MA, Vianna EN, Martins AS, Silva EF, Pesquero JL, Gomes MA. A single step duplex PCR to distinguish Entamoeba histolytica from Entamoeba dispar. Parasitology. 2004;128:625-8.

52. López-López P, Martínez-López MC, Boldo-León XM, Hernández-Díaz Y, González-Castro TB, Tovilla-Zárate CA, et al. Detection and differentiation of Entamoeba histolytica and Entamoeba dispar in clinical samples through PCR-denaturing gradient gel electrophoresis. Braz J Med Biol Res. 2017;50:e5997. 
53. Ali IK, Hossain MB, Roy S, Ayeh-Kumi PF, Petri WA Jr, Haque R, et al. Entamoeba moshkovskii infections in children, Bangladesh. Emerg Infect Dis. 2003;9:580-4

54. Royer TL, Gilchrist C, Kabir M, Arju T, Ralston KS, Haque R, et al. Entamoeba bangladeshi nov. sp., Bangladesh. Emerg Infect Dis. 2012;18:1543-5.

55. Verweij JJ, Stensvold CR. Molecular testing for clinical diagnosis and epidemiological investigations of intestinal parasitic infections. Clin Microbiol Rev. 2014;27:371-418.

56. Zebardast N, Haghighi A, Yeganeh F, Seyyed Tabaei SJ, Gharavi MJ, Fallahi S, et al. Application of multiplex PCR for detection and differentiation of Entamoeba histolytica, Entamoeba dispar and Entamoeba moshkovskii. Iran J Parasitol. 2014;9:466-73.

57. Persson S, de Boer RF, Kooistra-Smid AM, Olsen KE. Five commercial DNA extraction systems tested and compared on a stool sample collection. Diagn Microbiol Infect Dis. 2011;69:240-4.

58. Verkerke HP, Sobuz SU, Petri WA Jr. Molecular diagnosis of infectious diarrhea: focus on enteric protozoa. Expert Rev Mol Diagn. 2014;14:935-46.

59. Liu J, Gratz J, Amour C, Kibiki G, Becker S, Janaki L, et al. A laboratory-developed TaqMan Array Card for simultaneous detection of 19 enteropathogens. J Clin Microbiol. 2013;51:472-80.

60. Santos HL, Bandea R, Martins LA, de Macedo HW, Peralta RH, Peralta JM, et al. Differential identification of Entamoeba spp. based on the analysis of 18S rRNA. Parasitol Res. 2010;106:883-8.

61. Santos HL, Peralta RH, de Macedo HW, Barreto MG, Peralta JM. Com parison of multiplex-PCR and antigen detection for differential diagnosis of Entamoeba histolytica. Braz J Infect Dis. 2007;11:365-70.

62. Nazemalhosseini Mojarad E, Nochi Z, Sahebekhtiari N, Rostami Nejad M Dabiri H, Zali MR, et al. Discrimination of Entamoeba moshkovskii in patients with gastrointestinal disorders by single-round PCR. Jpn J Infect Dis. 2010;63:136-8

63. Zebardast N, Yeganeh F, Gharavi MJ, Abadi A, Seyyed Tabaei SJ Haghighi A. Simultaneous detection and differentiation of Entamoeba histolytica, E. dispar, E. moshkovskii, Giardia lamblia and Cryptosporidium spp. in human fecal samples using multiplex PCR and qPCR-MCA Acta Trop. 2016;162:233-8.

64. Anuar TS, Al-Mekhlafi HM, Ghani MK, Azreen SN, Md Salleh F, Ghazali $\mathrm{N}$, et al. First molecular identification of Entamoeba moshkovskii in Malaysia. Parasitology. 2012;139:1521-5.

65. Shimokawa C, Kabir M, Taniuchi M, Mondal D, Kobayashi S, Ali KM et al. Entamoeba moshkovskii is associated with diarrhea in infants and causes diarrhea and colitis in mice. J Infect Dis. 2012;206:744-51.

66. Gonin P, Trudel L. Detection and differentiation of Entamoeba histolytica and Entamoeba dispar isolates in clinical samples by PCR and enzyme-linked immunosorbent assay. J Clin Microbiol. 2003;41:237-41.

67. Hamzah Z, Petmitr S, Mungthin M, Leelayoova S, Chavalitshewinkoon-Petmitr P. Differential detection of Entamoeba histolytica, Entamoeba dispar, and Entamoeba moshkovskii by a single-round PCR assay. J Clin Microbiol. 2006;44:3196-200.

68. Khairnar K, Parija SC. A novel nested multiplex polymerase chain reaction (PCR) assay for differential detection of Entamoeba histolytica, $E$ moshkovskii and E. dispar DNA in stool samples. BMC Microbiol. 2007;7:47.

69. Ngui R, Angal L, Fakhrurrazi SA, Lim Ai LY, Ling LY, Ibrahim J, et al. Differentiating Entamoeba histolytica, Entamoeba dispar and Entamoeba moshkovskii using nested polymerase chain reaction (PCR) in rural communities in Malaysia. Parasit Vectors. 2012:5:187.

70. Bahrami F, Haghighi A, Zamini G, Khademerfan M. Differential detection of Entamoeba histolytica, Entamoeba dispar and Entamoeba moshkovs kii in faecal samples using nested multiplex PCR in west of Iran. Epidemiol Infect. 2019;147:e96.

71. ElBakri A, Samie A, Ezzedine S, Odeh RA. Differential detection of Entamoeba histolytica, Entamoeba dispar and Entamoeba moshkovskii in fecal samples by nested PCR in the United Arab Emirates (UAE). Acta Parasitol. 2013;58:185-90.

72. Haque R, Kabir M, Noor Z, Rahman SM, Mondal D, Alam F, et al. Diagnosis of amebic liver abscess and amebic colitis by detection of Entamoeba histolytica DNA in blood, urine, and saliva by a real-time PCR assay. J Clin Microbiol. 2010;48:2798-801.

73. Othman N, Mohamed Z, Verweij JJ, Huat LB, Olivos-García A, Yeng C et al. Application of real-time polymerase chain reaction in detection of Entamoeba histolytica in pus aspirates of liver abscess patients. Foodborne Pathog Dis. 2010;7:637-41.

74. Yap EP, Lo YM, Flemming KA, McGee JO. False-positives and Contamination in PCR. In: Griffin HG, Griffin AM, editors. PCR technology. Current innovations. Boca Raton: CRC Press; 1994.

75. Qvarnstrom Y, James C, Xayavong M, Holloway BP, Visvesvara GS Sriram R, et al. Comparison of real-time PCR protocols for differential laboratory diagnosis of amebiasis. J Clin Microbiol. 2005;43:5491-7.
76. Santos HL, Bandyopadhyay K, Bandea R, Peralta RH, Peralta JM, Da Silva AJ. LUMINEX®: a new technology for the simultaneous identification of five Entamoeba spp. commonly found in human stools. Parasit Vectors. 2013;6:69.

77. Cnops L, Esbroeck MV. Freezing of stool samples improves real-time PCR detection of Entamoeba dispar and Entamoeba histolytica. J Microbiol Methods. 2010;80:310-2

78. Forsell J, Koskiniemi S, Hedberg I, Edebro H, Evengård B, Granlund M. Evaluation of factors affecting real-time PCR performance for diagnosis of Entamoeba histolytica and Entamoeba dispar in clinical stool samples. J Med Microbiol. 2015;64:1053-62.

79. Hamzah Z, Petmitr S, Mungthin M, Leelayoova S, Chavalitshewinkoon-Petmitr P. Development of multiplex real-time polymerase chain reaction for detection of Entamoeba histolytica, Entamoeba dispar, and Entamoeba moshkovskii in clinical specimens. Am J Trop Med Hyg. 2010;83:909-13

80. ten Hove R, Schuurman T, Kooistra M, Möller L, van Lieshout $L$, Verweij JJ. Detection of diarrhoea-causing protozoa in general practice patients in The Netherlands by multiplex real-time PCR. Clin Microbiol Infect. 2007;13:1001-7.

81. Ali IKM, Roy S. A real-time PCR assay for simultaneous detection and differentiation of four common Entamoeba species that infect humans. J Clin Microbiol. 2020;59:e01986-20.

82. Claas EC, Burnham CA, Mazzulli T, Templeton K, Topin F. Performance of the XTAG® gastrointestinal pathogen panel, a multiplex molecular assay for simultaneous detection of bacterial, viral, and parasitic causes of infectious gastroenteritis. J Microbiol Biotechnol. 2013;23:1041-5.

83. Shankar P, Mishra J, Bharti V, Parashar D, Singh S. Multiplex PCR assay for simultaneous detection and differentiation of Entamoeba histolytica, Giardia lamblia, and Salmonella spp. in the municipality-supplied drinking water. J Lab Physicians. 2019;11:275-80.

84. Guatelli JC, Whitfield KM, Kwoh DY, Barringer KJ, Richman DD, Gingeras TR. Isothermal, in vitro amplification of nucleic acids by a multienzyme reaction modeled after retroviral replication. Proc Natl Acad Sci USA. 1990;87:1874-8.

85. Compton J. Nucleic acid sequence-based amplification. Nature. 1991;350:91-2.

86. Walker GT, Fraiser MS, Schram JL, Little MC, Nadeau JG, Malinowski DP. Strand displacement amplification-an isothermal, in vitro DNA amplification technique. Nucleic Acids Res. 1992;20:1691-6.

87. Notomi T, Okayama H, Masubuchi H, Yonekawa, T, Watanabe K, Amino N, et al. Loop-mediated isothermal amplification of DNA. Nucleic Acids Res. 2000;28:E63.

88. Ai L, Li C, Elsheikha HM, Hong SJ, Chen JX, Chen SH, et al. Rapid identification and differentiation of Fasciola hepatica and Fasciola gigantica by a loop-mediated isothermal amplification (LAMP) assay. Vet Parasitol. 2010;174:228-33.

89. Xu J, Rong R, Zhang HQ, Shi CJ, Zhu XQ, Xia CM. Sensitive and rapid detection of Schistosoma japonicum DNA by loop-mediated isothermal amplification (LAMP). Int J Parasitol. 2010;40:327-31.

90. Nkouawa A, Sako Y, Li T, Chen X, Wandra T, Swastika IK, et al. Evaluation of a loop-mediated isothermal amplification method using fecal specimens for differential detection of Taenia species from humans. J Clin Microbiol. 2010;48:3350-2

91. Karanis P, Thekisoe O, Kiouptsi K, Ongerth J, Igarashi I, Inoue N. Development and preliminary evaluation of a loop-mediated isothermal amplification procedure for sensitive detection of Cryptosporidium oocysts in fecal and water samples. Appl Environ Microbiol. 2007;73:5660-2.

92. Rivera WL, Ong VA. Development of loop-mediated isothermal amplification for rapid detection of Entamoeba histolytica. Asian Pac J Trop Med. 2013;6:457-61.

93. Singh P, Mirdha BR, Ahuja V, Singh S. Loop-mediated isothermal amplification (LAMP) assay for rapid detection of Entamoeba histolytica in amoebic liver abscess. World J Microbiol Biotechnol. 2013;29:27-32.

94. Kubota R, Jenkins DM. Real-time duplex applications of loop-mediated AMPlification (LAMP) by assimilating probes. Int J Mol Sci. 2015;16:4786-99.

95. Foo PC, Nurul Najian AB, Muhamad NA, Ahamad M, Mohamed M, Yean Yean $\mathrm{C}$, et al. Loop-mediated isothermal amplification (LAMP) reaction as viable PCR substitute for diagnostic applications: a comparative analysis study of LAMP, conventional PCR, nested PCR (nPCR) and real-time PCR (qPCR) based on Entamoeba histolytica DNA derived from faecal sample. BMC Biotechnol. 2020;20:34.

96. Huston $C D$, Petri WA. Amebiasis: Clinical implications of the recognition of Entamoeba dispar. Curr Infect Dis Rep. 1999;1:441-7. 